\title{
Utilization of Prevention of Mother-to-Child Transmission of HIV Services and Associated Factors among Antenatal Care Attending Mothers in Sebeta Town, Central Ethiopia
}

\author{
Hailu Merga, Kifle Woldemichael, and Lamessa Dube \\ Department of Epidemiology, College of Health Sciences, Jimma University, Jimma, Ethiopia \\ Correspondence should be addressed to Hailu Merga; hailu.merga2014@gmail.com
}

Received 16 April 2016; Revised 31 July 2016; Accepted 18 August 2016

Academic Editor: Ronald J. Prineas

Copyright (C) 2016 Hailu Merga et al. This is an open access article distributed under the Creative Commons Attribution License, which permits unrestricted use, distribution, and reproduction in any medium, provided the original work is properly cited.

Background. HIV transmission from mother to child continues to be the major source of HIV infection among children under the age of fifteen. Targeting pregnant women attending antenatal clinics provides a unique opportunity for implementing prevention of mother-to-child transmission (PMTCT) programs against HIV infection of newborn babies. This study assessed utilization of PMTCT service of HIV and associated factors among ANC attending mothers. Methods. An institutional based cross-sectional study was conducted from February 20 to March 30, 2015, using exit interviews with 377 ANC attendees using consecutive sampling method. In-depth interviews with service provider were conducted to complement the quantitative data. Data were entered and analysed using EpiData and SPSS, respectively. Results. The prevalence of PMTCT service utilization was $86.9 \%$ in this study. Only $8.6 \%$ of respondents attended the facility for HCT. After controlling confounders using logistic regression, PMTCT service utilization was associated with age (25-34) of respondents (AOR $(95 \% \mathrm{CI})=0.46(0.22,0.97))$, mother's occupational status (being merchant AOR $(95 \% \mathrm{CI})=0.31(0.12,0.83)$, government employee AOR $(95 \% \mathrm{CI})=0.05(0.01,0.28)$, student $\mathrm{AOR}(95 \% \mathrm{CI})=0.1$ $(0.01,0.44)$, and daily laborer AOR $(95 \% \mathrm{CI})=0.13(0.05,0.33))$, husband's educational status (lack of formal education (AOR ( $95 \%$ $\mathrm{CI})=3.3(1.1,9.9)))$, having discussion with husband $(\mathrm{AOR}(95 \% \mathrm{CI})=6.1(2.6,14.1))$, partner tested $(\mathrm{AOR}(95 \% \mathrm{CI})=8.2(1.9$, $34.46)$ ), and being not satisfied with the service $(\operatorname{AOR}(95 \% \mathrm{CI})=0.46(0.2,0.99))$. Conclusions. This study revealed that utilization of HIV counseling and testing during antenatal care was high among pregnant women in Sebeta town. It highlights that focusing on improvement of quality and coverage of health services has significant effects on PMTCT service utilization. Effective use or uptake of ARV drug among HIV-positive pregnant women should be further investigated so that utilization will be enhanced.

\section{Introduction}

Transmission of human immune virus (HIV) from an infected mother to her child during pregnancy, labor, delivery, or breastfeeding is known as mother-to-child transmission and it has created enormous social and economic problems. This MTCT continues to be the major source of HIV infection among children under the age of fifteen. Thus, PMTCT of HIV through providing HCT services to all pregnant women is essential in HIV prevention strategies. The PMTCT, which has been at the front of global public health activities, is a high intervention and has huge potential to improve both child and maternal health. Targeting pregnant women attending ANC clinics provides a unique opportunity for implementing PMTCT programs against HIV infection of new born babies [1].

Due to a number of barriers for the implementation of PMTCT program, in 2010, it was estimated that only $45 \%$ of HIV-positive pregnant women in the Sub-Saharan Africa (SSA) had access to PMTCT program [2]. MTCT rates remain high in developing nations, particularly SSA countries where majority of HIV infected women of child bearing age live. Such high rates persist mostly due to lack of access to existing prevention interventions, lack of male involvement, 
and women not disclosing their status to their partners $[3,4]$. Mother-to-child transmission of HIV remains as one of the biggest concerns that needs to be dealt with in taking effective preventive measures and maximizing treatment, care, and support for needy HIV-positive pregnant mothers in order to save the life of large number of innocents in our developing country [5].

In 2013 in Ethiopia, there were an estimated 793,700 people living with HIV including 200,300 children. There were approximately 45,200 AIDS related deaths in 2013 and about 898,400 AIDS orphans in the same year [6]. Besides the dominant heterosexual transmission in Ethiopia, vertical transmission from mother to child accounts for more than 90\% of pediatric AIDS [7]. In Ethiopia, PMTCT program was started in 2001 and comprehensive national guideline was developed in 2007 [8]. In 2013, Ethiopia has introduced option B+ in accordance with WHO guideline. In 2014, in Ethiopia, 2,495 health facilities were providing PMTCT service and the proportion of pregnant women counseled and tested for PMTCT of HIV was $57.0 \%$. Though the number of health facilities providing PMTCT service has increased dramatically in Ethiopia, MTCT of HIV still remains to be a challenge for the country due to high missed opportunities and dropout rates in addition to low coverage and utilization of services $[6,8,9]$.

Mothers are afraid of being stigmatized by community members if receiving PMTCT services identifies them as $\mathrm{HIV}$ infected. Fear of such unintended disclosure may be an important reason why mothers fail to seek care for HIVexposed infants. Studies identified various barriers to the implementation of PMTCT of HIV including socioeconomic and cultural factors affecting the uptake of HCT services, initiation of ARV prophylaxis, and loss to follow-up after starting ARV for PMTCT [10]. A study conducted in Addis Ababa, Ethiopia, found that lack of awareness and knowledge about the availability and benefit of ANC/PMTCT services, shortage of PMTCT service providers, lack of adequate and separate room for PMTCT services, poor involvement of partners/husbands in ANC/PMTCT services, poor disclosure HIV status to partners, and psychological unpreparedness due to fear of being positive for HIV are the main barriers preventing mothers from HIV testing [11].

Oromia region has the highest number of women in need of PMTCT services but also very low prevalence of PMTCT service, indicating that further targeting within the region needs to be done. In 2013, proportion of pregnant women tested for HIV as part of PMTCT was $17 \%$ and proportion of pregnant women living with HIV who received ARVs for PMTCT was $11.9 \%$ [8]. As a result of limited studies, there is little information on the challenges and barriers to PMTCT service utilization in Sebeta town, especially in the context of scaling up this program. Additionally, the expansion of industries in this town and its surrounding makes the town overcrowded but poor in maternal health services as needed including PMTCT services and there are no rigorous research efforts to try to explain constraining factors for PMTCT service utilization among ANC attendees in health facilities of this town. Therefore, this study was aimed at assessing utilization of PMTCT and associated factors among pregnant women attending ANC clinics of public health facilities in Sebeta town. Such information provides evidence for the identification of those factors contributing to the poor implementation of PMTCT services and fills the policy gaps towards the improvement of HIV prevention and control strategies.

\section{Methods and Materials}

Institutional based cross-sectional study was conducted among pregnant mothers attending antenatal care in Sebeta town public health facilities, Oromia regional state, from February 20 to March 30, 2015. Sebeta town is one of the big towns in Oromia regional state, central Ethiopia, located $25 \mathrm{~km}$ to the South West of Addis Ababa, capital city of Ethiopia. The total population of the town as projected from the 2007 census was 111,148 [12]. There are about 22,924 women of reproductive age (15-49 years) while 3,833 are estimated to be pregnant women according to the town health office report. Administratively, the town is divided into eight broad kebeles (the smallest administration unit in Ethiopia). There are a total of 3 public health centers, 54 private clinics, and 22 pharmacies in the town.

The study population was pregnant women who visited the three public health centers for ANC services during the study period and PMTCT service providers of each health facility. The sample size calculation was based on a single population proportion formula by taking $57 \%$ proportion of pregnant women counseled and tested for PMTCT of HIV [9], 95\% significance level, 5\% margin of error, and $10 \%$ nonresponse rate. Since the size of source population was less than 10,000 , after using finite population correction factor, the final sample size was 377. Sample size allocation to the health facilities was proportional to the number of clients, considering average number of ANC attendants at each facility over the three months prior to the study period. The selection of pregnant women for the interview was based on consecutive sampling method until the sample size required for each facility was obtained. A woman was eligible if she was attending ANC clinic but excluded if she was seriously ill and unable to communicate at the time of the study.

Both quantitative and qualitative data collection approaches were used. Face-to-face exit interviewer giving questionnaires was employed to collect the data from ANC attending mothers. The questionnaire was first adapted in English language. Then, English version of the questionnaire was translated into local language Afan Oromo and back translated into English to check for its consistency. Finally, pretesting was conducted at Awash Health Center using $5 \%$ of the total sample size to identify any weakness in the structuring of the research instruments. Awash Health Center is situated in a neighboring town where the population shares similar attributes as that of Sebeta town population. The questionnaire mainly consisted of closeended with some open-ended questions addressing sociodemographic characteristics, reproductive history, knowledge and attitude about the MTCT of HIV, ANC visit, waiting time at the health facility, HCT, partner's HIV testing 
status, privacy and confidentiality, and satisfaction with the services.

The main outcome variable in this study was PMTCT service utilization. It was measured by participants response who reported to be counseled and offered voluntary HIV testing, were HIV tested, and took postcounseling. Knowledge about PMTCT service was measured by the participants' responses to 7 knowledge related questions related to MTCT/PMTCT. Correct responses were given a value of " 1 " and incorrect responses were given " 0 ." The sum and mean were computed. A respondent who scored equal to or above the mean is considered as having good knowledge or otherwise they are labeled as having poor knowledge. Satisfaction of clients was measured using 8-item scale and it has "yes" and "no" responses. After principal component analysis, it was dichotomized (satisfied and dissatisfied) and then used for description and to see association with dependent variable. Attitude of clients was measured using five-point Likert scale. The instrument has Likert scale from strongly disagree (1) to strongly agree (5) for positive statement. Then, principal component analysis was computed and dichotomized as (positive attitude and negative attitude) to see association with dependent variable.

To supplement the quantitative study with qualitative data, in-depth interviews with 14 purposively selected PMTCT service providers were conducted. Semistructured in-depth interview guides were prepared in English and translated into local language Afan Oromo. All health workers who were responsible for PMTCT programs of the respective sites were requested to be interviewed and tape recorded with explanation of the objectives of the study and verbal consent. Both quantitative and qualitative questionnaires were adapted from the Joint United Nations Programme on HIV/AIDS (UNAIDS) best practice collection after considerable modifications were made to assess potential service barriers.

Four data collectors with nursing and midwifery background who were not from the health centers were assigned for data collection. One-day training was given for data collectors and supervisor. The data collection was supervised by trained supervisor with experience in PMTCT service.

The collected data were checked for completeness, edited, cleaned, coded, and entered into EpiData version 3.1 and exported to SPSS version 21 for analysis. Descriptive analysis was performed and results were presented by tables, graphs, and charts. Bivariate analysis was run using logistic regression to identify candidate variables for multivariable analysis. Variables with $p$ value $<0.25$ in bivariate analysis were considered as candidates for multiple logistic regressions. Multiple logistic regressions were performed using backward stepwise method to identify factors independently associated with dependent variable. Strength of association was measured using odds ratio and 95\% confidence intervals. $p$ value $<0.05$ was considered statistically significant. Multicollinearity assessment was conducted using the means of Variation Inflation Factors (VIF $=1.14$ ) which indicated the absence of any significant collinearity between explanatory variables in the logistic regression model. The goodnessof-fit test (Omnibus Tests of Model Coefficients) of the final model was significant and the Hosmer and Lemeshow goodness-of-fit test was not significant as indicators of model appropriateness.

The qualitative data recorded from the in-depth interview were transcribed verbatim and translated from local language Afan Oromo into English language by the principal investigator. The transcribed data were read carefully, categorized, and summarized by thematic areas. The in-depth interview data were triangulated with the quantitative data.

Ethical approval and clearance were obtained from ethical review board of College of Health Sciences, Jimma University. Written permission was obtained from the Oromia Regional Health Bureau. Permission to conduct the study was also obtained from the town health office and health facilities. Verbal consent was obtained before interview from participants and they were informed that they have full right to discontinue or refuse to participate in the study. Answers to any questions were completely confidential.

\section{Results}

3.1. Sociodemographic Characteristics of Respondents. Out of 377 antenatal care attending mothers sampled for the study, 374 (99.2\% response rate) participated in the study and completed the questionnaire. Of the 374 women, majority $(83.2 \%)$ were living in Sebeta town. The age of pregnant women included in this study ranged between 18 and 40 years with mean $( \pm$ standard deviation $(S D))$ age of $25.2( \pm 4.7)$ years and $342(91.4 \%)$ were currently married. Among the respondents, 228 (61\%) were Orthodox and 92 (24.6\%) Muslim followed by $54(14.4 \%)$ protestants. The largest ethnic group was Oromo, $285(76.2 \%)$, followed by Amhara, 44 (11.8\%). Almost half $(50.3 \%)$ of the women had attended grade 7 and above while $212(56.7 \%)$ of the respondents were housewives by their occupation. Regarding the occupational status of mothers' husbands/partners, 152 (43.2\%) were daily laborers and 188 (50.3\%) had attended grades 9-12 and beyond by schooling. Out of the total study subjects, $256(68.1 \%)$ of mothers earn an average monthly income of less than 750 ETB (Table 1). A total of 14 service providers participated in the in-depth interviews. All of the in-depth interview participants had at least diploma level education with some form of on job training.

3.2. Obstetric Factors. Mothers were asked about their gestational age and the reasons for visiting the ANC clinic. The average gestational age of the current pregnancy was 25.7 weeks, while 183 (48.9\%) of the respondents were in their third trimester. More than half of the respondents (54.5\%) were multigravida and 170 (45.5\%) were primigravida. Regarding the number of alive children, 207 (55.3\%) of mothers had no parity while the rest had one or more parities (Table 2). The average number of visits to the current ANC facility was 2 times, in which 147 (39.3\%) had visited ANC once. The pregnant women were asked why they visited the antenatal care clinic in the current health facility, and only $32(8.6 \%)$ of the respondents visited the ANC for HIV test. Clients were asked about how they first came to the 
TABLE 1: Sociodemographic characteristics of ANC attending mothers in Sebeta town, 2015.

\begin{tabular}{|c|c|c|}
\hline \multirow{2}{*}{ Characteristics } & \multicolumn{2}{|c|}{ Frequency } \\
\hline & Number & Percent \\
\hline \multicolumn{3}{|l|}{ Place of residence } \\
\hline Sebeta town & 311 & 83.2 \\
\hline Out of Sebeta town & 63 & 16.8 \\
\hline \multicolumn{3}{|l|}{ Age of respondent (in years) } \\
\hline $15-24$ & 182 & 48.7 \\
\hline $25-34$ & 168 & 44.9 \\
\hline $35-44$ & 24 & 6.4 \\
\hline \multicolumn{3}{|l|}{ Religion } \\
\hline Orthodox & 228 & 61.0 \\
\hline Muslim & 92 & 24.6 \\
\hline Protestant & 54 & 14.4 \\
\hline \multicolumn{3}{|l|}{ Marital status } \\
\hline Currently married & 342 & 91.4 \\
\hline Not currently married & 32 & 8.6 \\
\hline \multicolumn{3}{|l|}{ Ethnicity } \\
\hline Oromo & 285 & 76.2 \\
\hline Amhara & 44 & 11.8 \\
\hline Silte & 16 & 4.3 \\
\hline Gurage & 12 & 3.2 \\
\hline Tigre & 9 & 2.4 \\
\hline Others* & 9 & 2.4 \\
\hline \multicolumn{3}{|l|}{ Educational status } \\
\hline Illiterate & 64 & 17.1 \\
\hline Able to write and read & 13 & 3.5 \\
\hline Grades $1-8$ & 109 & 29.1 \\
\hline Grade 9 and beyond & 188 & 50.3 \\
\hline \multicolumn{3}{|l|}{ Occupational status } \\
\hline Housewife & 214 & 57.2 \\
\hline Daily laborer & 83 & 22.2 \\
\hline Merchant & 61 & 16.3 \\
\hline Government employee & 9 & 2.4 \\
\hline Student & 7 & 1.9 \\
\hline \multicolumn{3}{|c|}{ Husbands/partners occupational status ${ }^{\dagger}$} \\
\hline Daily laborer & 152 & 43.2 \\
\hline Merchant & 96 & 27.3 \\
\hline Government employee & 37 & 10.5 \\
\hline Driver & 31 & 8.8 \\
\hline Carpenter & 20 & 5.7 \\
\hline Others ${ }^{* *}$ & 16 & 4.5 \\
\hline \multicolumn{3}{|c|}{ Husband/partner educational status ${ }^{\dagger}$} \\
\hline No formal education & 53 & 15.1 \\
\hline Primary education & 87 & 24.7 \\
\hline Secondary and above & 212 & 60.2 \\
\hline \multicolumn{3}{|l|}{ Monthly income } \\
\hline$\leq 750$ & 118 & 31.6 \\
\hline$>750$ & 256 & 68.4 \\
\hline
\end{tabular}

${ }^{\dagger}$ Total does not add up to $374 ;{ }^{*}$ Welane, Kembata; ${ }^{* *}$ drivers, carpenter, farmers, and jobless.
TABLE 2: Gestational age and reasons for visiting the ANC clinic among ANC attending mothers, Sebeta, Oromia region, 2015.

\begin{tabular}{lcc}
\hline \multirow{2}{*}{ Characteristics } & \multicolumn{2}{c}{ Frequency } \\
& Number & Percent \\
\hline Gestational age in week & 26 & 7.0 \\
$\quad$ First trimester & 165 & 44.1 \\
$\quad$ Second trimester & 183 & 48.9 \\
$\quad$ Third trimester & & \\
Gravidity & 170 & 45.5 \\
$\quad$ Primigravida & 204 & 54.5 \\
$\quad$ Multigravida & & \\
Parity & 207 & 55.3 \\
$\quad$ No parity & 167 & 44.7 \\
$\quad$ One or more parities & & \\
Number of visits made to ANC clinic & 147 & 39.3 \\
$\quad$ One & 125 & 33.4 \\
$\quad$ Two & 102 & 27.3 \\
$\quad$ Three and more & & \\
Reason for visiting the ANC clinic & 32 & 8.6 \\
$\quad$ For both ANC service and HIV test & 342 & 91.4 \\
$\quad$ For ANC service only &
\end{tabular}

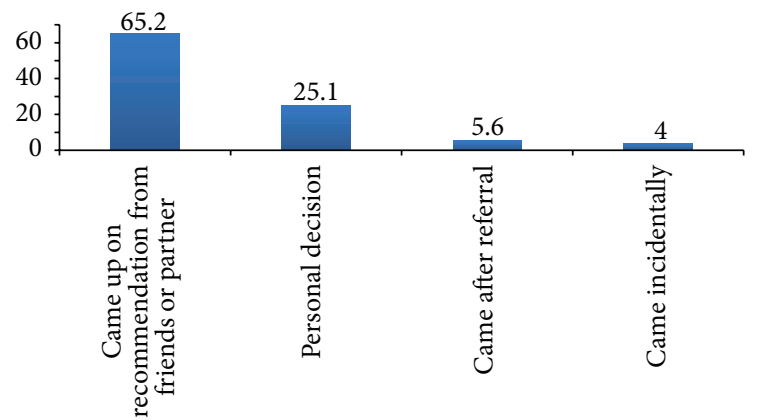

FIGURE 1: How the pregnant women came to visit the health facility where they had antenatal care for the first time, Sebeta, 2015.

health institution they visited and $65.2 \%$ of them reported that their visit was upon recommendation from their friends or partners. Only $25.1 \%$ of clients came by their personal decision (Figure 1).

3.3. Knowledge and Attitude of Respondents about MTCT of HIV. Overall, 243 (64.9\%) of the respondents had good knowledge of MTCT/PMTCT service while 131 (35.1\%) had poor knowledge. Two hundred twenty-nine $(61.2 \%)$ of the respondents had positive attitude while $145(38.8 \%)$ had negative attitude towards PMTCT service (Table 3 ).

In support of this finding, one service provider said

Even though awareness of mothers on MTCT of $H I V$ is increasing from time to time, still some mothers don't have awareness and knowledge especially about the ways of transmission and its prevention methods. (Age of 27, service provider) 
TABLE 3: Knowledge about MTCT of HIV among ANC attending mothers, Sebeta, 2015.

\begin{tabular}{|c|c|c|}
\hline \multirow{2}{*}{ Characteristics } & \multicolumn{2}{|c|}{ Frequency } \\
\hline & Number & Percent \\
\hline \multicolumn{3}{|c|}{$\begin{array}{l}\text { HIV can be transmitted from mother } \\
\text { to her child }\end{array}$} \\
\hline Yes & 279 & 74.6 \\
\hline No & 55 & 10.7 \\
\hline Did not know & 40 & 14.7 \\
\hline \multicolumn{3}{|c|}{ MTCT of HIV during pregnancy } \\
\hline Yes & 356 & 95.2 \\
\hline No & 18 & 4.8 \\
\hline \multicolumn{3}{|c|}{ MTCT of HIV during child birth } \\
\hline Yes & 124 & 33.2 \\
\hline No & 250 & 66.8 \\
\hline \multicolumn{3}{|c|}{ MTCT of HIV during breastfeeding } \\
\hline Yes & 108 & 28.9 \\
\hline No & 266 & 71.1 \\
\hline \multicolumn{3}{|c|}{$\begin{array}{l}\text { MTCT of HIV prevention by ARV } \\
\text { drug }\end{array}$} \\
\hline Yes & 150 & 40.1 \\
\hline No & 224 & 59.9 \\
\hline \multicolumn{3}{|c|}{$\begin{array}{l}\text { MTCT of HIV prevention by } \\
\text { avoiding breastfeeding }\end{array}$} \\
\hline Yes & 145 & 38.8 \\
\hline No & 229 & 61.2 \\
\hline \multicolumn{3}{|c|}{$\begin{array}{l}\text { MTCT of HIV prevention by } \\
\text { caesarian section delivery }\end{array}$} \\
\hline Yes & 28 & 7.5 \\
\hline No & 346 & 92.5 \\
\hline
\end{tabular}

3.4. PMTCT Service Utilization. About 325 (86.9\%) of the respondents reported that they had been tested for HIV during the current pregnancy either in the current health facility or elsewhere. However, $13.1 \%$ of the participants were not tested during the current pregnancy and the main reasons for not being tested were claimed to be the absence of counselor/service provider and lack of awareness and knowledge (Table 4). Regarding the test results, 313 (96.3\%) tested negative while $12(3.7 \%)$ tested positive.

One service provider stated the following:

Some of them may return home without testing due to lack of resource (man power/professionals and sometimes kit). They are appointed to afternoon or the next day due to lack of professional and service delivery room. Because according to $B P R$, the structure of man power for our health center is not compared with the population in the catchment area. On the other hand occasionally some of them refuse to be tested because they fear their husbands. (Female service provider)
TABLE 4: Respondent's practice of HIV testing and main reasons for being not tested and collection of ARV drug among ANC attending mothers in Sebeta town, Oromia region, 2015.

\begin{tabular}{|c|c|c|}
\hline \multirow{2}{*}{ Variable } & \multicolumn{2}{|c|}{ Frequency } \\
\hline & Number & Percent \\
\hline \multicolumn{3}{|l|}{$\begin{array}{l}\text { Respondents tested for HIV in the current } \\
\text { pregnancy }\end{array}$} \\
\hline Yes & 325 & 86.9 \\
\hline No & 49 & 13.1 \\
\hline \multicolumn{3}{|l|}{ HIV test result } \\
\hline Negative & 313 & 96.3 \\
\hline Positive & 12 & 3.7 \\
\hline \multicolumn{3}{|l|}{$\begin{array}{l}\text { Respondents' main reason for not being } \\
\text { tested }\end{array}$} \\
\hline Absence of counselor/provider/KIT & 26 & 53 \\
\hline Fear of rejection by partner/husband & 14 & 28.6 \\
\hline Lack of awareness and knowledge & 12 & 24.5 \\
\hline Fear of stigma and discrimination & 6 & 12.2 \\
\hline Tested before current pregnancy & 11 & 22.4 \\
\hline Fear of being tested positive for HIV & 1 & 2 \\
\hline \multicolumn{3}{|l|}{ Collected ARV drug } \\
\hline Yes & 9 & 75 \\
\hline No & 3 & 25 \\
\hline \multicolumn{3}{|l|}{$\begin{array}{l}\text { Respondents' main reason for not } \\
\text { collecting } A R V \text { drug }\end{array}$} \\
\hline Fear of her partner/husband & 1 & 33.3 \\
\hline Refusing her test result & 2 & 66.7 \\
\hline
\end{tabular}

Among those pregnant mothers of positive test result, only nine had collected ARV drug; but 3 (25\%) did not. The reasons for not collecting the drugs were fear of partner, refusing test result, and fear of stigma and discrimination. One midwifery nurse said

Some of them cry when they hear their HIV test result; they refuse their test result and said they should be tested at another health Institution. Hence, they refuse to collect ARV drugs or take it secretly and incorrectly due to fear of divorce, stigma or violence. Some of them change their address and disappear after they learned that they are HIV-positive due to the fear of stigma and discrimination. (Female service provider)

3.5. HCT Status of Pregnant Mothers' Partners/Husbands. The pregnant women were asked if they knew their partners' HIV testing status, and only about $24 \%$ of the respondents reported their partners were tested during the current pregnancy. However, about three-fourths, 266 (75.6\%), of the respondents' partners were not tested for HIV and the respondents thought the reasons include the following: their partners lack time, 174 (65.4\%), live in other areas, 52 (19.5\%), and lack awareness and knowledge, 34 (12.8\%). However, only 
two respondents said they did not know the reason why their partners were not tested. A service provider noted

\begin{abstract}
Mothers fear to be tested alone and there is a problem on how to include their partners/husbands in this programme. We give appointment and invitation letter to their partners to come together but the partners usually don't come for HCT. (Female service provider)
\end{abstract}

Regarding the discussion about ANC and HIV test with their partner, $296(84.1 \%)$ of the pregnant women interviewed said they had discussions with their current partners/husbands. Of the total respondents, 288 (97\%) thought that their partners/husbands had positive attitudes towards ANC services and HIV testing during pregnancy.

3.6. Waiting Time for the Services and Satisfaction with ANC/PMTCT Service. Time spent on waiting and discussion with ANC/PMTCT counselor/provider was assessed among pregnant women, and the mean waiting time spent was 81.7 minutes. About half of the respondents, 186 (49.7\%) spent between 30 and 60 minutes while only 37 (9.9\%) spent less than 10 minutes before seeing the counselor (Table 5). The mean waiting time for clients with their health care providers was 11.6 minutes and the range is calculated to be 40 minutes. Majority, 322 (86.1\%), of the respondents spent 5 to 15 minutes with counselors to get the service. Overall, the result showed that the time spent for waiting the service was significantly higher than the time spent for consultation with service providers. More than half, 215 (57.5\%), of the respondents said that the time they spent during the visit was too much.

Almost all of in-depth interview participants admitted the problem of long waiting time and short consultation time. They discussed that lack of space or room was the main barrier:

Shortage of health workers had contributed to the long waiting time and too short consultation time. Even some of them come in the morning and wait for the service throughout the day. Since there is only one room for the service and they spend more time with HIV positive mothers thus couldn't address all clients.

Overall, 302 (80.7\%) of pregnant mothers attending ANC reported being satisfied by the ANC/PMTCT service they received while 72 (19.3\%) were not satisfied.

One service provider said

It is difficult to talk about full satisfaction with the service having human power and service provision room shortages. Due to this some of them get the service after waiting throughout the day while others may be appointed to the next day. But technically, our professionals are competent to provide the service and they were trained on PMTCT (option B+). So we hope that we are satisfying them technically. (Male service provider)
TABLE 5: Time spent by pregnant women waiting and with counselor among ANC attending mothers, Sebeta town, 2015.

\begin{tabular}{lcc}
\hline \multirow{2}{*}{ Characteristics } & \multicolumn{2}{c}{ Frequency } \\
& Number & Percent \\
\hline Waiting time to see the counselor & 37 & \\
$\quad$ Less than 30 minutes & 186 & 49.9 \\
31-60 minutes & 64 & 17.1 \\
61-90 minutes & 87 & 23.3 \\
More than 90 minutes & & \\
Time spent with counselor/provider & 322 & 86.1 \\
5-15 minutes & 52 & 13.9 \\
>15 minutes & & \\
Amount of time spent during the visit & 215 & 57.5 \\
Too long & 141 & 37.7 \\
Reasonable (just right) & 18 & 4.8 \\
Too short & & \\
\hline
\end{tabular}

Generally, the qualitative study showed that inadequate maternal health services, shortage of man power, inadequate training of professionals in some health centers, poor male involvement, lack of separate and adequate room for the services, and inadequate satisfaction of mothers towards service due to waiting for long time were major barriers to the uptake of ANC/PMTCT services.

3.7. Factors Associated with PMTCT Service Utilization. Factors independently associated with PMTCT utilization were age, occupational status, partner's educational status, having discussion with partners, satisfaction with the service, and partner's HIV test status (Table 6). This study revealed that partner's educational status, having discussion with partners, and partner's HIV test status were predictive (increase the service utilization or positively affect the service utilization) but age of mothers, mothers' educational status, and mothers' satisfaction with the service were protective that is why they were barriers or hinder mothers from utilizing PMTCT service.

Older women (25-34) were 54\% less likely to utilize the service as compared to younger ones (15-24) $(\mathrm{AOR}=0.46$ (95\% CI: $0.22,0.97)$ ). Housewives were more likely to utilize the service than merchants $(\mathrm{AOR}=0.31(95 \% \mathrm{CI}: 0.12,0.83))$, government employees $(\mathrm{AOR}=0.05$ (95\% CI: 0.01, 0.28)), students $(\mathrm{AOR}=0.1(95 \% \mathrm{CI}: 0.01,0.44))$, and daily laborers $(\mathrm{AOR}=0.13(95 \% \mathrm{CI}: 0.05,0.33))$. Women whose husbands/partners did not attend any formal education were 3.3 times more likely to utilize PMTCT service when compared with those who attended secondary and above schooling $(\mathrm{AOR}=3.3$ (95\% CI: 1.1, 9.9)). Women who had discussed ANC use and HIV testing with their current partners were about 6 times more likely to utilize PMTCT service compared to those who had not $(\mathrm{AOR}=6.1(95 \% \mathrm{CI}: 2.6,14.1))$. Similarly, women whose partners were tested for HIV during their current pregnancy were 8 times more likely to utilize PMTCT service when compared to those whose partners were not tested $(\mathrm{AOR}=8.2(95 \% \mathrm{CI}: 1.9,34.5))$. Women who were not satisfied by the service were $54 \%$ less likely to utilize PMTCT 
TABLE 6: Multiple logistic regression analysis showing predictors of PMTCT service utilization ANC attending pregnant mothers, Sebeta, 2015 .

\begin{tabular}{|c|c|c|c|c|c|}
\hline \multirow{2}{*}{ Characteristics } & \multicolumn{2}{|c|}{ PMTCT service utilization } & \multirow{2}{*}{ COR $(95 \% \mathrm{CI})$} & \multirow{2}{*}{$\operatorname{AOR}(95 \% \mathrm{CI})$} & \multirow{2}{*}{$p$ value } \\
\hline & Yes, $n(\%)$ & No, $n(\%)$ & & & \\
\hline \multicolumn{6}{|l|}{ Age of respondent } \\
\hline $15-24$ & $165(50.7)$ & $17(34.7)$ & 1.0 & 1.0 & \\
\hline $25-34$ & $137(42.2)$ & $31(63.3)$ & $0.45(0.24,0.86)$ & $0.46(0.22,0.97)$ & $0.04^{*}$ \\
\hline $35-44$ & $23(7.1)$ & $1(2)$ & $2.4(0.3,18.66)$ & $1.7(0.19,15.6)$ & 0.62 \\
\hline \multicolumn{6}{|l|}{ Occupational status } \\
\hline Housewife & $200(61.5)$ & $14(28.6)$ & 1.0 & 1.0 & \\
\hline Merchant & $52(16.0)$ & $9(18.4)$ & $0.4(0.17,0.98)$ & $0.31(0.12,0.83)$ & $0.02^{*}$ \\
\hline Government employee & $5(1.5)$ & $4(8.2)$ & $0.1(0.02,0.36)$ & $0.05(0.01,0.28)$ & $0.001^{*}$ \\
\hline Student & $4(1.2)$ & $3(6.1)$ & $0.1(0.02,0.46)$ & $0.1(0.01,0.44)$ & $0.005^{*}$ \\
\hline Daily laborer & $64(19.7)$ & $19(38.8)$ & $0.24(0.11,0.5)$ & $0.13(0.05,0.33)$ & $<0.001^{*}$ \\
\hline \multicolumn{6}{|l|}{ Husband educational status } \\
\hline No formal education & $68(20.9)$ & $7(14.3)$ & $2.1(0.71,6.23)$ & $3.3(1.1,9.9)$ & $0.032^{*}$ \\
\hline Primary education & $76(23.4)$ & $11(22.4)$ & $1.2(0.57,2.48)$ & $1.23(0.51,2.99)$ & 0.64 \\
\hline Secondary and above & $181(55.7)$ & $31(63.3)$ & 1.0 & 1.0 & \\
\hline \multicolumn{6}{|c|}{ Respondents discussion with their current partner } \\
\hline Yes & $268(82.5)$ & $29(59.2)$ & $4.5(2.3,8.9)$ & $6.1(2.6,14.1)$ & $<0.0001^{*}$ \\
\hline No & $57(17.5)$ & $20(40.8)$ & 1.0 & 1.0 & \\
\hline \multicolumn{6}{|c|}{ Respondents partners HIV tested } \\
\hline Yes & $84(25.8)$ & $2(4.1)$ & $13.6(2.8,65.9)$ & $8.2(1.9,34.46)$ & $0.004^{*}$ \\
\hline No & $241(74.2)$ & $47(95.9)$ & 1.0 & 1.0 & \\
\hline \multicolumn{6}{|l|}{ Service satisfaction } \\
\hline Satisfied & $270(83.1)$ & $32(65.3)$ & 1.0 & 1.0 & \\
\hline Not satisfied & $55(16.9)$ & $17(34.7)$ & $0.38(0.2,0.74)$ & $0.46(0.2,0.99)$ & $0.04^{*}$ \\
\hline
\end{tabular}

* Statistically significant variables at $p<0.05$; COR: crude odds ratio; OR: adjusted odds ratio; CI: confidence interval.

service when compared with those who were satisfied by the service $(\mathrm{AOR}=0.46(95 \% \mathrm{CI}: 0.2,0.99))$.

\section{Discussion}

The study highlights a number of issues useful for understanding level and factors associated with the utilization of PMTCT services at public health facilities in Sebeta town. As for the part of ANC service, the study showed potential areas for the improvement of PMTCT intervention. In this study, the PMTCT service utilization among ANC attendees was found to be $86.9 \%$ while $13.1 \%$ were not tested for HIV. This study is consistent with the study conducted in Gondar, north-west Ethiopia, that showed $82.5 \%$ of pregnant women accepted HIV counseling and testing [13]. The finding of this result is higher than the 2014 national coverage (57\%) [9] but is lower than reports from different parts of Ethiopia: Addis Ababa (94\%) [11], Hawassa (96.1\%) [14], and South Omo Zone (96.5\%) [15]. The possible reasons for this could be due to the fact that the program being implemented in opt-out approach is with high level of acceptability and high level of awareness towards PMTCT.

Among the sociodemographic variables, age of mothers was significantly associated with utilization of PMTCT service. Older women (25-34) were 54\% less likely to utilize
PMTCT service as compared to younger ones (15-24). This finding is consistent with the study conducted in Dire Dawa, East Ethiopia, in which older age groups (30 years and above) were more likely to accept VCT as compared to those younger (19 years and below) [16] and in Gondar, northwest Ethiopia, in which 15-24 aged mothers were 5.6 more likely to accept PITC in the ANC clinics [13]. But a study conducted in Debre Markos, north-west Ethiopia, reported that sociodemographic variables showed no association [17] and another study conducted in Nigeria showed teenagers were 3 times less likely to utilize the service when compared with the older women [18]. This could be that younger and older women may differ in their perceived risk of HIV and understanding of the importance of HIV testing.

Another sociodemographic variable which had association with PMTCT service utilization in this study was mother's occupational status. Mothers who were housewives were more likely to utilize PMTCT service than women in other occupational categories in this study. But the finding contradicted with the study conducted in Dire Dawa, where employed women were 4 times more likely to be tested than unemployed women [16]. The findings of this study also contradicted with the study conducted in Debre Markos town which affirmed that government and privately employed pregnant women were eight and four times more likely to be ready when compared with the housewives, respectively [19]. 
The difference might be due to the awareness creation activity made up to household level by health extension workers and health development army.

This study also revealed that mothers whose husbands/partners did not attend formal education were 3.3 times more likely to utilize PMTCT service when compared with those who attended secondary and above schooling. This finding is contradicted with the study conducted in East Hararghe Zone, Ethiopia, which showed mothers who had a partner educated beyond the elementary level were 3.3 times more likely to utilize than elementary level [20]. The possible reason might be that they may have awareness on these issues from different media sources including awareness in the community by health extension workers, health development army, and one to five network systems in Ethiopia.

This study showed $74.6 \%$ of mothers knew that mother with HIV can pass the virus to her baby and 150 (40.1\%) of them knew it can be prevented by ARV drug. This finding is lower than the study conducted in a similar setting in Addis Ababa, Ethiopia (90.3\%) [11], Hawassa Referral Hospital, Ethiopia (90.1\%) [14], and Uganda (93\%) [21] but consistent with the study conducted in East Gojjam, Ethiopia (77.5\%) [22], and Sudan (79\%) [23]. Overall, about 65\% of mothers had good knowledge in this study which is higher than report from Northwestern Ethiopia (42\%) [19] but lower than another report (79.5\%) from Dire Dawa [16]. This might be due to the fact that health education program implementation and community awareness about MTCT vary from region to region. This level of knowledge may be due to various health education programmes being conducted at health facility and awareness created at community levels in collaboration with health extension workers and health development army.

Clients' average waiting time and average duration of stay with their health care providers were 82 minutes and 12 minutes, respectively. According to this study, even some of them were appointed to the next day after waiting for a long period of time, as noted from qualitative study from service providers: "Since there is shortage of man power and service delivery room some of the clients are waiting for long time; even appointed to the next day." The average waiting time in this finding was by far higher than the study in Adama that reported that clients' average waiting time and average duration of stay with their health care provider were 24.5 minutes and 12.8 minutes, respectively [24]. This finding is consistent with a study conducted in Addis Ababa which reported that time spent for waiting the service (more than 30 minutes) was significantly longer than the time spent for consultation with service providers (12 minutes) [11]. The magnitude of this problem might be due to large number of clients registering for ANC at some health facilities and shortage of man power (service providers).

This study revealed that only $25 \%$ of mothers' husbands/partners were tested for HIV during their current pregnancy. Multiple logistic regressions showed respondents who had discussion about ANC and HIV testing with their husbands were about 6 times more likely to utilize PMTCT service when compared with those who had no discussion with their partners. This finding is consistent with the research conducted in Gambella that showed that women who did not discuss with their husbands HIV testing was about eight and half times more likely to refuse HIV testing than those who had discussed it with their husbands [25]. Similarly, respondents whose partners were tested for HIV during current pregnancy were about 8 times more likely to utilize PMTCT service which is similar to the report from Botswana [26]. This finding is consistent with the study from Addis Ababa, Adama, and Malawi [11, 24, 27]. Studies conducted in East Gojjam Zone [22], Mekelle [28], Hawassa Referral Hospital [14], and Addis Ababa [11] showed that the level of male involvement in ANC/PMTCT was 15.7\%, 20.1\%, $52.7 \%$, and $60 \%$, respectively. Majority of pregnant mothers face difficulty in deciding to initiate ARV due to lack of male involvement which has been considered as one of the main barriers in PMTCT service utilization. Due to this, most HIV tested mothers do not disclose their HIV serostatus due to fear of divorce, domestic violence, or being abandoned by their husbands or families.

Client satisfaction is one of the factors affecting PMTCT service utilization. Overall in this study a high proportion, $80.7 \%$, of clients reported that they were satisfied with the service they had received and those who were not satisfied by the service were $54 \%$ less likely to utilize PMTCT service $(\mathrm{AOR}=0.46(95 \% \mathrm{CI}: 0.2,0.99))$. A study from Gambella also confirmed that clients who were less satisfied with the service were six times more likely to refuse HIV test than those who were more satisfied with the service [25]. In order to improve the utilization of ANC/PMTCT services, consideration should be given to improve quality of the services. Similarly, $61.1 \%$ of mothers had positive attitude towards PMTCT service utilization which is lower than $72.8 \%$ reported from Sudan [23] and 97.4\% from Hawassa Referral Hospital [14]. Although attitude did not show statistically significant association in this study, a study from Dire Dawa [16] and Gondar [13] showed mothers who had positive attitude towards HIV testing were nine times and about six times more likely to accept voluntary HIV testing, respectively, than those who had negative attitudes.

This study has some limitations. The study was health facility based and the pregnant women do not represent the general population of this town because only mothers seeking ANC at health centers were eligible for the study. Similarly, ANC attendant pregnant mothers were selected on consecutive sampling methods.

In conclusion, this study revealed that PMTCT of HIV service utilization is high among ANC attendees and knowledge of mothers about MTCT/PMTCT of HIV was also high. Male partners' HIV counseling and testing during the current pregnancy were reported to be low. Age of mother, mother's and her husband's occupational status, having discussion with partner, male involvement, and satisfaction with the service were associated with PMTCT service utilization. Waiting for a long time for the service, lack of awareness and knowledge about the MTCT, PMTCT service providers' shortage, lack of adequate and separate room for this services, and fear of being HIV-positive were the main barriers preventing mothers from PMTCT service utilization. Based on the finding of this study, improving quality of the services and strengthening mother to mother group and health development army as well 
as health extension workers to increase awareness creation on ANC/MTC/PMTCT for the community up to bottom household level and providing community based health education by targeting male involvement in ANC/PMTCT services are recommended. Effective use or uptake of ARV drug among HIV-positive pregnant women should be further investigated.

\section{Abbreviations}

AIDS: Acquired Immune Deficiency Syndrome

ANC: Antenatal care

ARV: Antiretroviral drugs

HAPCO: HIV/AIDS Prevention and Control Office

HCT: HIV counseling and testing

HIV: Human Immunodeficiency Virus

MOH: Ministry of Health

MTCT: Mother-to-child transmission of HIV

NVP: Nevirapine

PMTCT: Prevention of mother-to-child transmission of HIV

SSA: $\quad$ Sub-Saharan Africa

UNAIDS: Joint United Nations Programme on AIDS

UNGASS: United Nations General Assembly Special Session on AIDS

UNICEF: United Nations Children's Fund

VCT: Voluntary counseling and testing

WHO: World Health Organization.

\section{Competing Interests}

The authors declare that they have no competing interests.

\section{Authors' Contributions}

All Hailu Merga, Kifle Woldemichael, and Lamessa Dube are involved in the study from the inception to design, acquisition of data, analysis and interpretation, and drafting of the manuscript.

\section{Acknowledgments}

The authors would like to extend their deepest gratitude to Jimma University for financing this study. The authors wish to express their sincere thanks to Wakgari Deressa, Solomon G/Michael, and Fekede Endale, the data collectors and supervisors. The authors are especially grateful to health facility authorities, ANC/PMTCT service providers, and all pregnant women who participated in this study. This would not have been possible without their involvement.

\section{References}

[1] WHO, PMTCT Strategic Vision: Preventing Mother-to-Child Transmission of HIV to Reach the UNGASS and Millennium Development Goals, WHO, Geneva, Switzerland, 2010.

[2] WHO, "Towards Universal Access: scaling up priority HIV/ AIDS interventions in the health sector," Progress Report, WHO, Geneva, Switzerland, 2010.
[3] A. Hardon, E. Vernooij, G. Bongololo-Mbera et al., "Women's views on consent, counseling and confidentiality in PMTCT: a mixed-methods study in four African countries," BMC Public Health, vol. 12, no. 1, article 26, 2012.

[4] F. W. Kalembo, D. Yukai, M. Zgambo, and Q. Jun, "Male partner involvement in prevention of mother to child transmission of HIV in Sub-Saharan Africa: successes, challenges and way forward," Open Journal of Preventive Medicine, vol. 2, no. 1, pp. 35-42, 2012.

[5] A. Adedimeji, N. Abboud, B. Merdekios, and M. Shiferaw, "A qualitative study of barriers to effectiveness of interventions to prevent mother-to-child transmission of HIV in Arba Minch, Ethiopia," International Journal of Population Research, vol. 2012, Article ID 532154, 7 pages, 2012.

[6] Federal Democratic Republic of Ethiopia HIV Prevention and Control Office, Country Progress Report on the HIV Response, Federal Democratic Republic of Ethiopia HIV Prevention and Control Office, Addis Ababa, Ethiopia, 2014.

[7] T. Nigatu and Y. Woldegebriel, "Analysis of the prevention of mother-to-child transmission (PMTCT) service utilization in Ethiopia: 2006-2010," Reproductive Health, vol. 8, no. 1, article 6, 2011.

[8] Ministry of Health of Federal Democratic Republic of Ethiopia, National Strategic Plan for Elimination of Mother to Child Transmission of HIV (e-MTCT of HIV) 2013-2015, Ministry of Health of Federal Democratic Republic of Ethiopia, Addis Ababa, Ethiopia, 2013.

[9] Ministry of Health of Federal Democratic Republic of Ethiopia, "Health sector development programme Iv," Annual Performance Report, Ministry of Health of Federal Democratic Republic of Ethiopia, Addis Ababa, Ethiopia, 2014.

[10] E. Muniu and M. Karama, "Barriers to uptake and effective integration of PMTCT into SRH services in selected Health facilities in Nairobi County, Kenya," International Journal of Pediatrics \& Neonatal Care, vol. 1, no. 4, pp. 3-7, 2014.

[11] W. Deressa, A. Seme, A. Asefa, G. Teshome, and F. Enqusellassie, "Utilization of PMTCT services and associated factors among pregnant women attending antenatal clinics in Addis Ababa, Ethiopia," BMC Pregnancy and Childbirth, vol. 14, no. 1, article 328, 2014.

[12] Central Statistical Agency, The 2007 National Census Preliminary Report for Ethiopia, Central Statistical Agency, Addis Ababa, Ethiopia, 2007.

[13] M. T. Malaju and G. D. Alene, "Assessment of utilization of provider-initiated HIV testing and counseling as an intervention for prevention of mother to child transmission of HIV and associated factors among pregnant women in Gondar town, North West Ethiopia," BMC Public Health, vol. 12, article 226, 2012.

[14] A. A. Abajobir and A. B. Zeleke, "AIDS \& clinical knowledge, attitude, practice and factors associated with prevention of mother-to-child transmission of HIV/AIDS among pregnant mothers," Journal of AIDS \& Clinical Research, vol. 4, no. 6, 2013.

[15] W. Godana, "Prevalence of HIV/AIDS and its Associated Factors among Prevention of Mother-to-Child Transmission (PMTCT) Service Users in Jinka Town Health Institutions, South Omo Zone, South Ethiopia," Science Journal of Public Health, vol. 1, no. 3, article 125, 2013.

[16] A. Demissie, A. Deribew, and M. Abera, "Determinants of acceptance of voluntary HIV testing among antenatal clinic attendees at Dil Chora Hospital, Dire Dawa, East Ethiopia," 
Ethiopian Journal of Health Development, vol. 23, no. 2, pp. 142$147,2010$.

[17] G. Tsegay, M. Edris, and S. Meseret, "Assessment of voluntary counseling and testing service utilization and associated factors among Debre Markos University Students, North West Ethiopia: a cross-sectional survey in 2011," BMC Public Health, vol. 13, no. 1, article 243, 2013.

[18] O. E. Amoran, O. F. Salami, and F. A. Oluwole, "A comparative analysis of teenagers and older pregnant women in the utilization of prevention of mother to child transmission [PMTCT] services in, Western Nigeria," BMC International Health and Human Rights, vol. 12, no. 1, article 13, 2012.

[19] Z. Moges and A. Amberbir, "Factors associated with readiness to VCT service utilization among pregnant women attending Clinics in Northwestern Ethiopia: a Health belief model approach," Ethiopian Journal of Health Sciences, vol. 21, no. 5, pp. 115-122, 2007.

[20] D. Wagaw, A. Tamiru, and K. Lulu, "Beyond Prong 3: factors influencing PMTCT service utilization in East Hararge Zone, Oromia Region, Ethiopia," in Proceedings of the 20th International AIDS Conference, Melbourne, Australia, 2014.

[21] G. Harms, K. Schulze, I. Moneta, C. Baryomunsi, P. Mbezi, and G. Poggensee, "Mother-to-child transmission of HIV and its prevention: awareness and knowledge in Uganda and Tanzania," SAHARA-J: Journal of Social Aspects of HIV/AIDS, vol. 2, no. 2, pp. 258-266, 2005.

[22] A. Belachew and G. Abebe, "Factors affecting acceptance of HIV Counseling \& Testing among antenatal care attendants: with Emphasis on Role of Male Partners," International Journal of Scientific and Engineering Research, vol. 3, no. 4, 2012.

[23] M. M. Mahmoud, A. M. Nasr, D. E. A. Gassmelseed, M. A. Abdalelhafiz, M. A. Elsheikh, and I. Adam, "Knowledge and attitude toward HIV voluntary counseling and testing services among pregnant women attending an antenatal clinic in Sudan," Journal of Medical Virology, vol. 79, no. 5, pp. 469-473, 2007.

[24] A. Asefa and G. Mitike, "Prevention of Mother-to-Child Transmission (PMTCT) of HIV services in Adama town, Ethiopia: clients' satisfaction and challenges experienced by service providers," BMC Pregnancy and Childbirth, vol. 14, no. 1, article 57, 2014.

[25] W. Fanta and A. Worku, "Determinants for refusal of HIV testing among women attending for antenatal care in Gambella Region, Ethiopia," Reproductive Health, vol. 9, no. 1, article no. 8, 2012.

[26] T. Creek, R. Ntumy, L. Mazhani et al., "Factors associated with low early uptake of a national program to prevent mother to child transmission of HIV (PMTCT): results of a survey of mothers and providers, Botswana, 2003," AIDS and Behavior, vol. 13, no. 2, pp. 356-364, 2009.

[27] A. L. Nyondo, A. S. Muula, and A. F. Chimwaza, "Assessment of strategies for male involvement in the prevention of mother-tochild transmission of HIV services in Blantyre, Malawi," Global Health Action, vol. 6, Article ID 22780, 2013.

[28] F. Haile and Y. Brhan, "Male partner involvements in PMTCT: a cross sectional study, Mekelle, Northern Ethiopia," BMC Pregnancy and Childbirth, vol. 14, no. 1, article 65, 2014. 


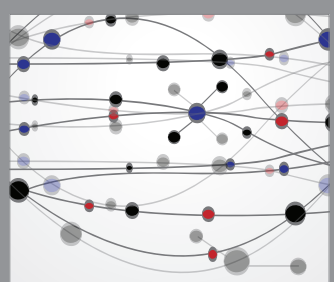

The Scientific World Journal
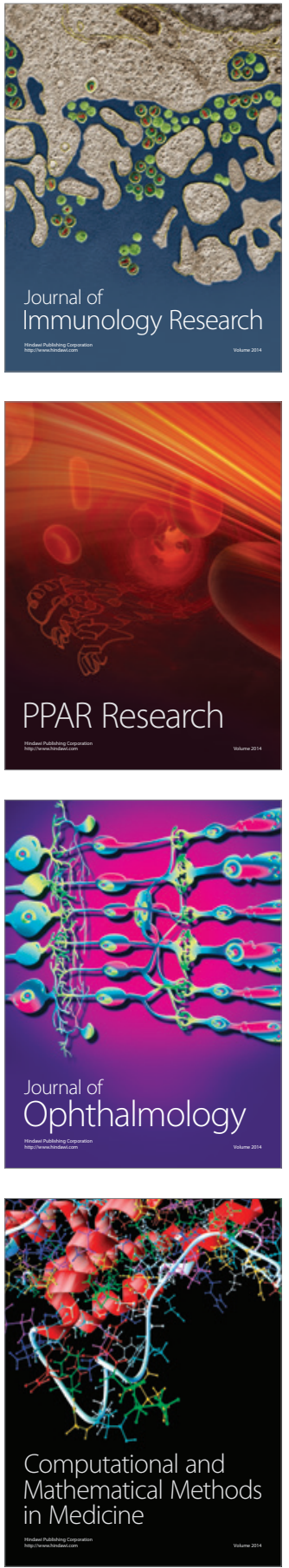

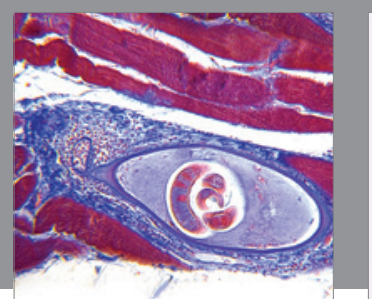

Gastroenterology Research and Practice

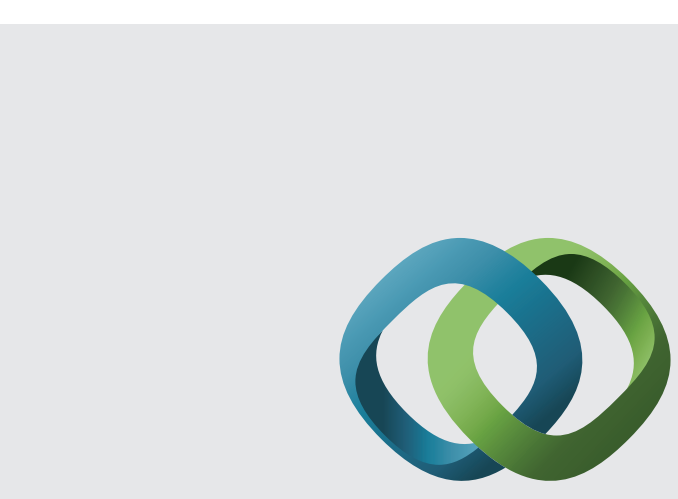

\section{Hindawi}

Submit your manuscripts at

http://www.hindawi.com
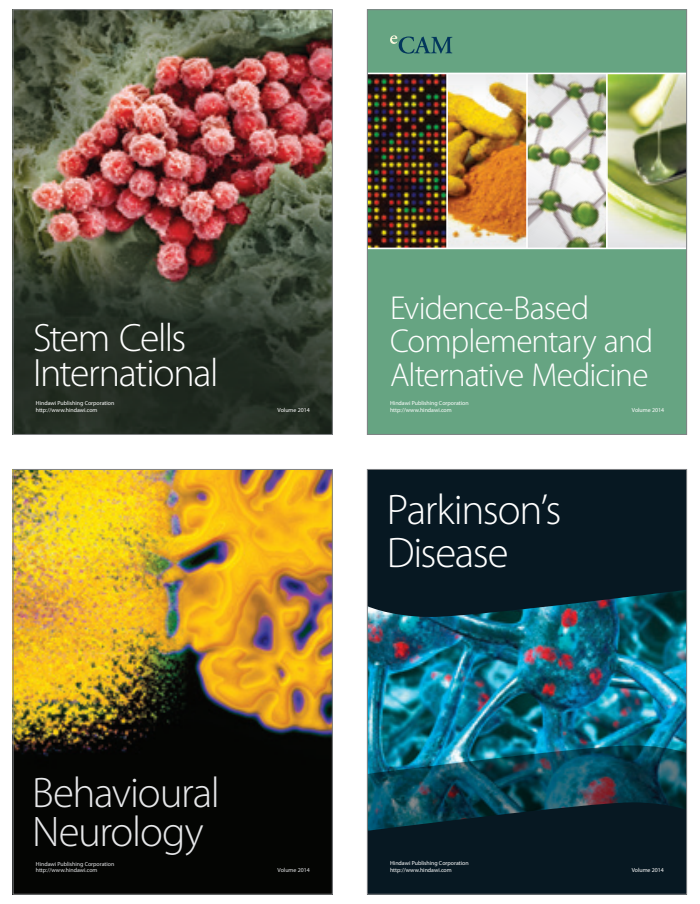
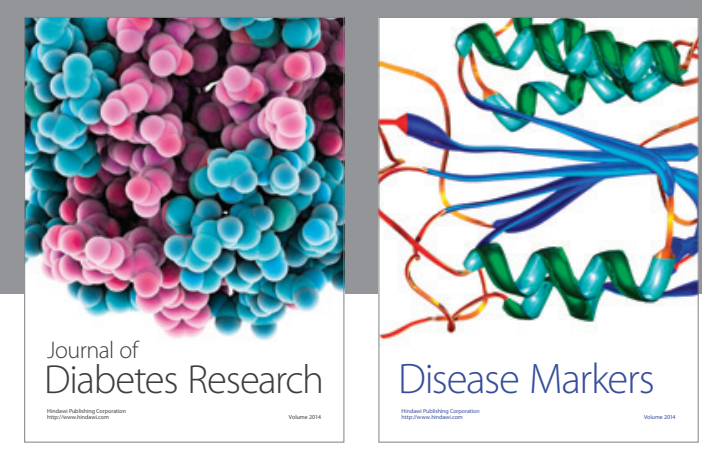

Disease Markers
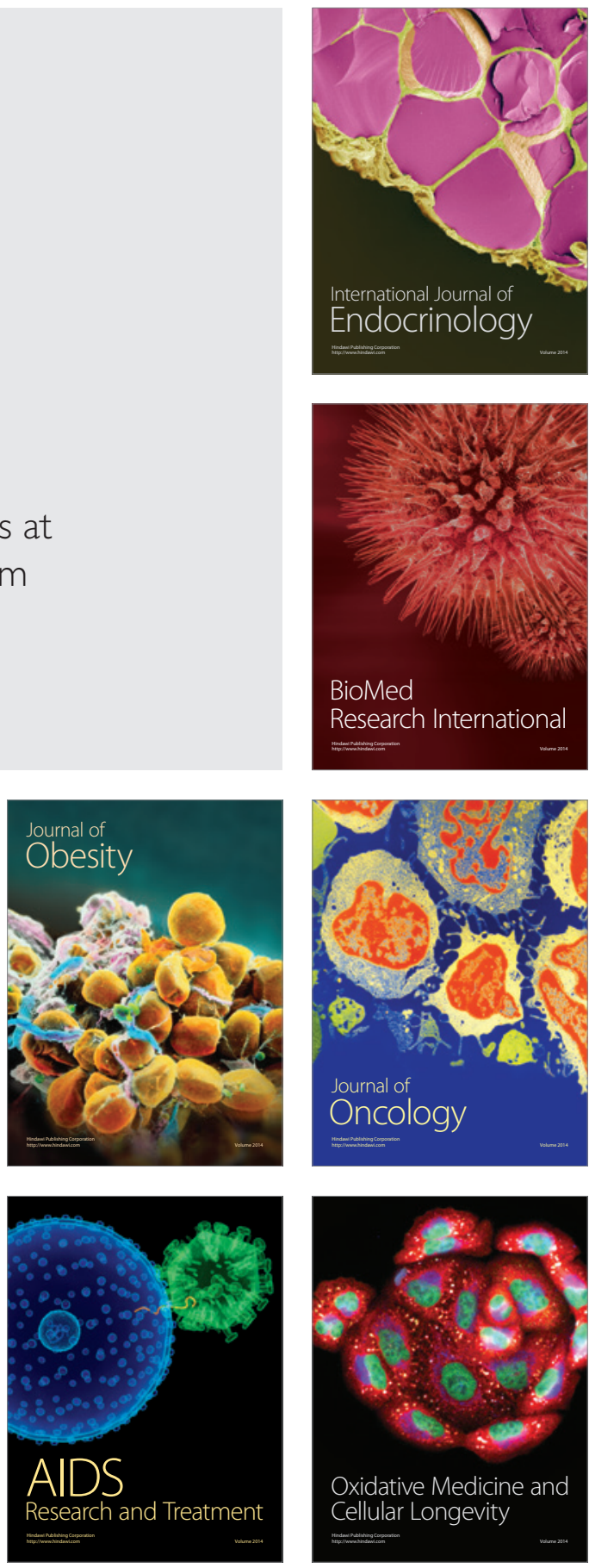